\title{
Sobre las infancias, un recorrido con algunas preguntas y diversas respuestas posibles a partir del disco Por qué por qué del grupo Canticuénticos
}

\author{
María Laura Kiener; María Valentina \\ Morande; Lara Yost \\ Universidad Nacional del Litoral (UNL, Argentina).
}

El grupo musical Canticuénticos surgió en la ciudad de Santa Fe, Argentina, en el año 2007. Está integrado por los artistas Daniela Ranallo, Laura Ibáñez, Ruth Hillar, Daniel Bianchi, Gonzalo Carmelé y Nahuel Ramayo, y produce música, no exclusiva pero sí especialmente, para las infancias. Han editado cuatro discos: Canticuénticos embrujados (2009), Nada en su lugar (2013), Algo que decirte (2015) y Por qué por qué (2018). Los caracteriza la fusión de estilos musicales propios del cancionero popular argentino y latinoamericano (chacareras, chamarritas, huaynos, cumbias, chamamé, entre otros).
Tal fusión busca tender puentes entre el patrimonio cultural regional y el público de la niñez. Dice Ruth Hillar al respecto:

Creemos que en Argentina y Latinoamérica tenemos un patrimonio musical muy valioso y muy bello, y es nuestra responsabilidad cuidarlo y hacerlo crecer. Quisiéramos que nuestras canciones sean una puerta de entrada por la que los chicos pasen a encontrarse con una música que les pertenece, que les da identidad, que les habla en su idioma y que está ahí, no para mirarla como a una pieza de museo, sino para seguir reinventándola siempre. ${ }^{\mathrm{I}}$ 

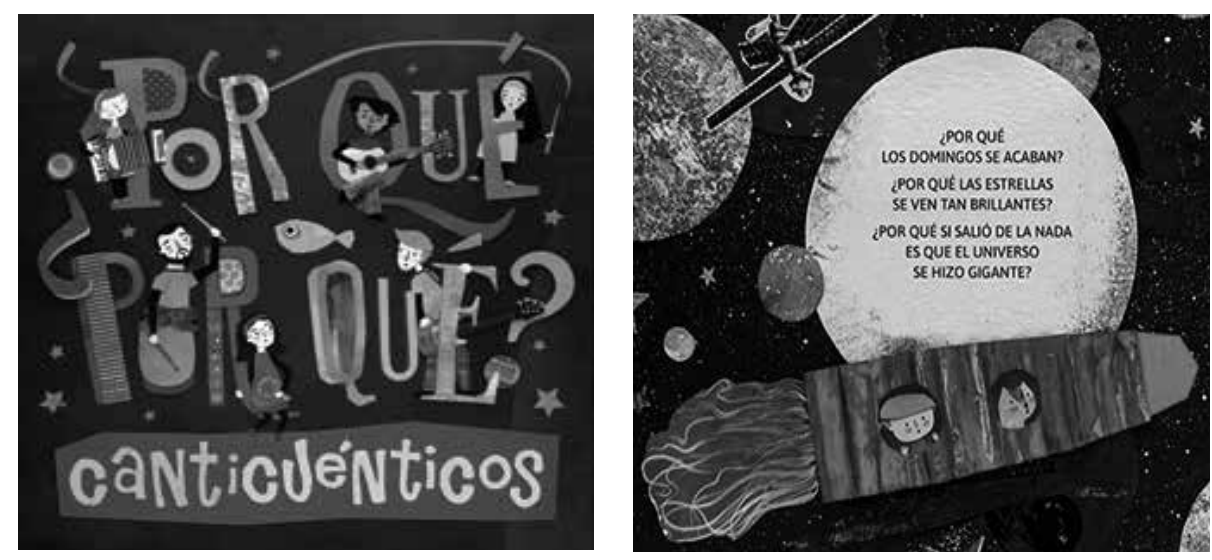

En este sentido, son destacables los hipotextos retomados por el grupo: María Elena Walsh, Luis María Pescetti, los Musiqueros, Violeta Parra y Ramón Ayala entre muchos otros forman parte de esta serie. De este modo, sostienen los músicos, se promueve el acceso de los niños y niñas a textos de la cultura de origen diverso, que trascienden el ámbito infantil. ${ }^{2}$

El último disco de la banda, Por qué por qué, fue lanzado en abril de 2018 por Gobi Music y está integrado por 19 piezas que incluyen canciones y diálogos.

La canción que inaugura y titula el CD inaugura también una serie de interrogantes que, desde la aparente ingenuidad, desmantelan la configuración del sujeto niño en tanto oyente pasivo (frecuente en otras producciones destinadas al público infantil), para proponerlo y potenciar-

lo, ahora, en tanto sujeto de derecho y reflexión.

Es destacable que la canción ofrezca preguntas pero no sugiera respuestas, dado que justamente la potencialidad de esas respuestas radica en su condición de no-dichas, es decir, en su posibilidad de estar-por decirse. Esto habilita, asimismo, que la imaginación de los oyentes resignifique esos espacios. Además, es pertinente tener en cuenta que el modo de enunciar las preguntas (y la composición en sí de la totalidad de las letras) contempla y se constituye de acuerdo a las posibilidades de su destinatario: así, el texto está poblado de objetos concretos y situaciones cotidianas. Esto último, sin embargo, no implica que las preguntas sean simples o que la cultura tenga una respuesta relativamente consensuada, 
sino que, por lo contrario, el horizonte de las respuestas da lugar al conflicto.

Nos detenemos puntualmente en las inquietudes sobre el trabajo infantil («¿Por qué algunos niños trabajan? ¿Por qué si el trabajo es cosa de grandes?»), las relaciones de poder ( ¿iPor qué siempre hay alguien que manda?») y la diversidad de subjetividades ( ¿Por qué cada persona es diferente?»), además de cuestiones relacionadas con el tiempo que comparten los adultos a cargo con los nińos ("¿Por qué te vas temprano y tarde volvés?»). Por un lado, entonces, se resignifica y revitaliza al niño como sujeto crítico y, por el otro, se desestabilizan concepciones hegemónicas (como pueden entenderse tal vez las reflexiones sobre el trabajo y el sistema capitalista).

Asimismo, las canciones del disco, cada una a su modo, promueven el $e x-$ trañamiento (Shklovksi, 1970) frente a la materialidad de la lengua; es así como, a través de diversos procedimientos composicionales, la «subvierten" y ponen en evidencia su condición de signo. Por ejemplo, la aliteración es central en la musicalidad de La rana Rosita ( Rema que rema la rana Rosita/ rumbea el río canoa chiquita»); mientras que la deixis es tomada como tema en $A c a ́$ tá, donde se retoma el habla coloquial infantil («dónde están las manos / dónde están los pies / dónde está escondido ese sonido que no se ve / acá tá acá tá»). De este modo, se abre la puerta a una mirada lúdica sobre el lenguaje y se habilita a mirar «extradisco»: es decir, se vuelve la mirada a lo cotidiano, pero es una mirada desnaturalizada.

En La chacarera jeringosa se sugiere, a través de la introducción de una lengua-otra (el jeringoso) que descoloca por ser desconocida para una de las participantes, que si lo importante es lograr la comunicación y el entendimiento de (y con) el otro, el aprendizaje de una lengua (a) parece tan sencillo como jugar.

Otro procedimiento destacable es la intervención en los afijos flexivos de los nombres que designan entidades humanas. En la canción Juntes hay que jugar, precedida por una grabación en la que se pone en cuestión a quién se incluye cuando se dice, por ejemplo, «juntos». La letra de la canción mencionada tematiza, a través de «una palabra que nos incluya [a chicos y chicas]», cómo el lenguaje habilita a los sujetos en la medida que los nombra. «Juntes» es el término elegido, que a su vez está imbrincado en la letra de una canción que discute los roles de género tradicionales. Así, Juntes hay que jugar da cuenta, también, del lenguaje como lugar para la problematización crítica de las prácticas sociales. En el cuerpo de la canción, podemos apreciar el uso de ambos géneros (nene/nena) distanciándose del uso normativo del masculino. A su vez, se entrelaza con tópicos en discusión como el tipo de colores o juegos que «le pertenecen» a cada 
niño: «Si voy a ser capitana no preciso ese disfraz/ de princesita rosada que me querés regalar». «Son tan poquitos colores el celeste y rosa/ Pintemos un arcoíris de color libertad». Detenernos en el título Juntes hay que jugar es relevante porque se plantea la revisión del género no marcado en español (el masculino) que, como sabemos, es lo "correcto" y parte del deber ser de nuestra lengua (gramática normativa), pero, en este caso, va acompañado de una expresión deóntica «hay que» (obligación). Esto último nos resulta curioso dado que la modalización predica sobre una construcción "anómala» (que cae fuera de la regla), como si «juntes» se propusiera ahora como el deber ser que antes imponía «juntos». La «deonsis» queda, de este modo, resignificada por su contexto anterior y posterior: por un lado, admite una lectura «irónica» en la medida en que está precedida por un uso no normativo del lenguaje (¿cuál es el valor del deber ser en una formulación cuya primera palabra no lo respeta?). Por el otro, el objeto de la predicación deóntica (jugar) es un fin en orden a la ampliación del horizonte de lo posible. Es decir, es un imperativo que, en lugar de conservar el orden actual, da la posibilidad de modificarlo o intervenirlo.

La canción está precedida por un diálogo que anticipa y justifica la elección del lenguaje inclusivo, diálogo en el que se pone de manifiesto que tal vez no es tan «lógico» que juntas se refiera sólo a las mujeres, pero juntos a hombres y mujeres, además de poder especificarse para decir sólo hombres. Es por esto que se busca «una palabra que nos junte» $y$, como si fuera un juego con este último verbo, se les ocurre juntes, adoptando el lenguaje inclusivo.

Por otra parte, las prácticas de esta banda pueden entenderse como una nano-intervención, en términos de Gerbaudo y Tosti (2017), es decir, como una de esas "pequeñísimas operaciones responsables», que rozan lo espectacular pero también están vinculadas a la "pequeña tarea». Intervenciones que, a su vez, están surcadas por la fantasía, lo cual deja en evidencia el arrojo de cada movimiento dado, lo que implica el poder de decisión de quienes responden. En este caso, uno de los objetivos es acercar a los niños un patrimonio cultural que les es propio (desde lo litoraleño, lo argentino y lo latinoamericano), y que cada canción sea una puerta de entrada para imaginar, pensar y preguntar.

Asimismo, todo el trabajo del grupo en general pero las canciones de este CD en particular se caracterizan por no imponer interpretaciones únicas o dirigidas, sino que, al contrario, dan lugar a múltiples interpretaciones. Dejan espacios vacíos para que los resignifique quien escucha o lee. En este sentido, estas producciones se distinguen de otras que pueblan el consumo infantil y que, muchas veces, plantean una lectura unidireccional. Como dicen Cañón y Hermida en el texto ya citado 
de Gerbaudo y Tosti: "Trabajamos en pos de una práctica que se aleja de la univocidad y del consumo utilitarista de los textos literarios y favorece en cambio un abordaje plural y crítico, propio de la recepción artística» (2017:89). Esto puede ampliarse hasta traspasar lo estrictamente literario y abarcar lo artístico, como concluye la cita. Es relevante el hincapié en promover un abordaje crítico, más pensando en el niño, porque significa correrlo del lugar que socialmente tiene, asociado a la pasividad e ingenuidad, y proponerle, en cambio, uno más activo. Así, la intervención particular que se construye en el disco, anticipada ya en el nombre, es la de ofrecer preguntas, en primer lugar, a las infancias e invitar Así, entonces, es importante considerar un aspecto central vinculado a la politización del sujeto-niño, ya que en estas canciones los niños pueden participar de los temas de la esfera pública. No encontramos una línea divisoria entre «temas para niños» y "temas para adultos», sino que se exponen temáticas acorde a problemas que nos atañen a todos y a todas, independientemente de la edad. Las canciones, desde la selección léxica (las palabras que aparecen), promueven la participación de los niños en tópicos como: sexualidad, trabajo infantil, lenguaje inclusivo, abusos, etc. Una canción que refuerza esta cuestión es Hay secretos, donde se percibe con claridad la relación niño-adulto, en tanto el adulto es quien ayuda a expresar lo que no se puede decir, quien acompańa, y no el único autorizado para hablar («Acá estoy quiero ayudarte/ sé que decís la verdad// ya no habrá que andar con miedo/ siempre te voy a cuidar»).

Por otro lado, pero en igual relación con el concepto de sujeto activo con el que se asocia ahora al niño, se ponen a disposición diversas plataformas (audiovisual, musical, dramático-teatral, soporte escrito) con las cuales el niño tiene la posibilidad de plantear su propio recorrido de lectura. Desde la página web de Canticuénticos, ${ }^{3}$ podemos ver que se encuentran habilitados tanto los distintos discos con sus respectivas canciones, como los libros que las acompañan, con las cuales se puede interactuar a medida que se establece una relación más estrecha con el grupo musical. De esta manera, se pone a disposición de los espectadores una experiencia estética que recupera diversos lenguajes. 


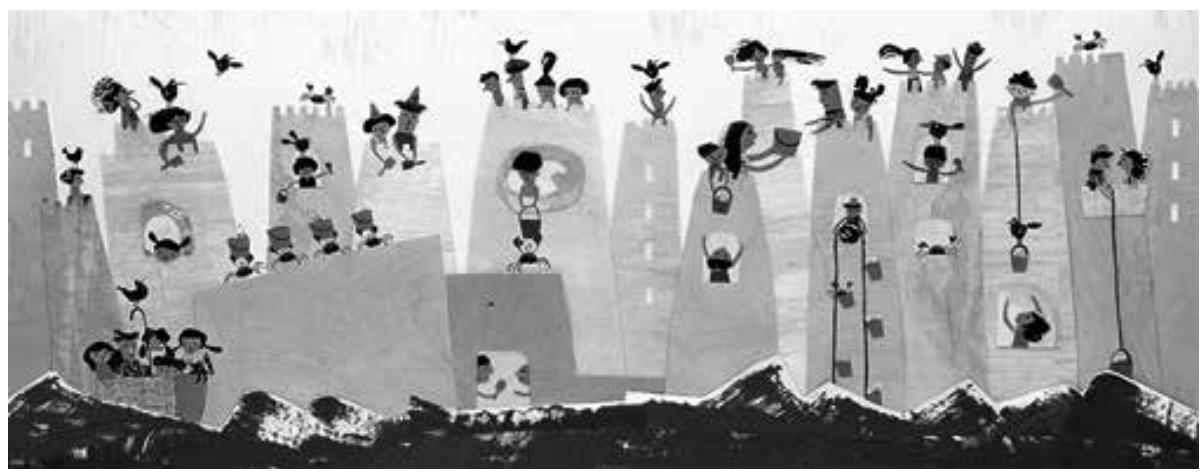

A modo de cierre, queremos retomar lo que dice Bombini (2005): «LLo que está en juego es un presente posible de inclusión para que los chicos, pero también muchos ciudadanos, no queden afuera, no sean relegados y no se autoconvenzan de que hay un mundo que no les pertenece». Esta cita nos habilita a decir que lo que está en juego es muy valioso y, si se quiere, también muy urgente, porque se trata nada más y nada menos de que nadie quede afuera. Creemos que este es uno de los objetivos principales del trabajo de Canticuénticos, lograr que los chicos y las chicas (pero también los adultos) confíen en que pueden ocupar los espacios que quieran, que no hay limitaciones.

Referencias bibliográficas

- BOMBINI, G. (2005). Sentido y eficacia de las políticas públicas de promoción de la lectura. Encuentros. 15 años del Ce.Pro.Pa.Lij (pp. 29-42). Santa Cruz: Manuscritos Libros.

- CAÑÓN, M. Y HERMIDA, C. (2017). Jitanjáfora. Crear redes a través del lenguaje y la literatura. En Gerbaudo, A. y Tosti, I. (Eds.). Nano-intervenciones con la literatura y otras formas de arte. Facultad de Humanidades y Ciencias, Universidad Nacional del Litoral. Libro digital, PDF.

4 En Sentido y eficacia de las políticas públicas de promoción de la lectura, citado en la compilación de Gerbaudo y Tosti (2017). 
• HUMPHREY, I.(2016). "El fenómeno canticuénticos" diario La Nación, sección espectáculo [en línea]. Consultado en https:// www.lanacion.com.ar/espectaculos/teatro/el-fenomeno-canticuenticos-nid1920242

- GERBAUDO, A.; TOSTI, I.[et al.] (2017). Nano-intervenciones con la literatura y otras formas de arte. Santa Fe. Ed: Universidad Nacional del Litoral: Facultad de Humanidades y Ciencias. Libro digital, PDF.

•SHKLOVSKI, V.(1970). "El arte como artificio" en La teoría de la literatura de los formalistas rusos compilado por Tinianov,

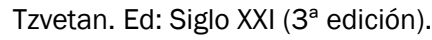

